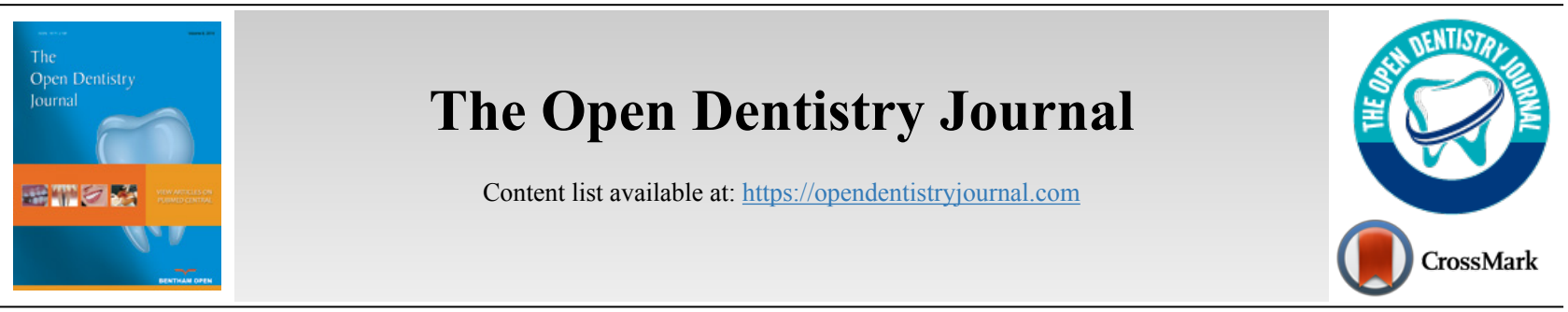

RESEARCH ARTICLE

\title{
Effect of Finishing and Polishing on The Surface Roughness of Bulk Fill Composites
}

Abdullah Aljamhan ${ }^{1}$, Syed Rashid Habib ${ }^{2, *}$, Mohammed A. AlSarhan ${ }^{3}$, Bashayer AlZahrani ${ }^{4}$, Hessa AlOtaibi ${ }^{4}$ and Norah AlSunaidi $^{4}$

${ }^{1}$ Restorative Dental Sciences department, College of Dentistry, King Saud University, Riyadh, Saudi Arabia

${ }^{2}$ Department of Prosthetic Dental Sciences, College of Dentistry, King Saud University, Riyadh, Saudi Arabia

${ }^{3}$ Department of Periodontics and Community Dentistry, College of Dentistry, King Saud University, Riyadh, Saudi Arabia

${ }^{4}$ Dental University Hospital, King Saud University Medical City, Riyadh, Saudi Arabia

\begin{abstract}
:
Objective:

The aim of this in vitro study was to compare the effect of three finishing/polishing systems on the surface roughness (Ra) of conventional and Bulk-fill composite resins.

\section{Materials and methods:}

The Ra values of three different brands of Bulk-fill composites (Filtek Bulk-fill ${ }^{\circledR}, 3 \mathrm{M}$ ESPE; SonicFill Bulk-fill ${ }^{\circledR}$, Kerr; SDR Bulk-fill ${ }^{\circledR}$, Dentsply) were tested and compared with the Ra of a conventional composite (Filtek XT Z350 ${ }^{\circledR}$, 3M ESPE). A total of 30 discs $(10 \mathrm{~mm} \times 2 \mathrm{~mm}) \mathrm{were}$ fabricated from four test materials and divided into three groups $(n=10 /$ group $)$ depending on the three finishing/polishing systems used (Astropol $^{\circledR}$, Ivoclar Vivadent; PoGo ${ }^{\circledR}$, Dentsply; Sof-LexTM ${ }^{\circledR}, 3 \mathrm{M}$ ESPE). The Ra of each specimen was recorded with an optical profilometer (Contour-GT- $\mathrm{X}^{\mathbb{1}}$, USA). ANOVA and Tukey's tests were used for statistical analysis.

Results:

Statistically significant differences $(\mathrm{P}<0.05)$ were observed between the Ra values of all composite materials tested with three finishing/polishing systems. Among composite materials, only Group-III showed a significant difference $(\mathrm{P}=0.003)$ in Ra obtained using all three finishing/polishing systems. SDR Bulk-fill ${ }^{\circledast}$ and Filtek XT Z350 ${ }^{\circledast}$ showed the highest $(0.810 \pm 0.373 \mu \mathrm{m})$ and lowest $(0.365 \pm 0.119 \mu \mathrm{m})$ Ra values, respectively. Individually, the highest Ra was recorded for SDR Bulk-fill ${ }^{\circledR}$ when it was finished/polished with the Astropol ${ }^{\circledR}$ system. SonicFill Bulk-fill $^{\circledR}$ and SDR Bulk-fill ${ }^{\circledast}$ composites exhibited the lowest Ra values when they were finished with the PoGo ${ }^{\circledR}$ system.

\section{Conclusion:}

Finishing and polishing techniques greatly affect the surface roughness of different Bulk-fill composites because variations in the surface roughness were observed for all tested composite materials. Filtek XT Z350 ${ }^{\circledast}$ exhibited the lowest surface roughness, while SDR Bulk-fill ${ }^{\circledR}$ exhibited the highest surface roughness among the tested composite materials.
\end{abstract}

Keywords: Composite, Bulk-fill composites, Dental restorations, Composite fillings, Finishing system, Polishing system.

\begin{tabular}{l|l|l|r} 
Article History & Received: June 19, 2020 & Revised: December 18, 2020 & Accepted: December 22, 2020
\end{tabular}

\section{INTRODUCTION}

For many years, composite resins have allowed clinicians to provide esthetic and strong restorations to their patients as an

* Address correspondence to this author at Department of Prosthetic Dental Sciences, College of Dentistry, King Saud University, P. O. Box 60169, King Abdullah Road, Riyadh, 11545, Saudi Arabia; Tel: 966-1-467 7230;

Mobile: 966-534750834; Fax: 966-1-467 8548;

E-mail: rashidhabib@hotmail.com; syhabib@ksu.edu.sa alternative to amalgam fillings [1]. However, there are several advantages of using regular composites; specifically, dentists have to spend more time and effort on placing composite resin restorations because the composite has to be placed in increments to ensure proper depth for the curing light, which makes it difficult to achieve good adaptation to cavity walls [2]. Manufacturers have begun to address this concern by introducing new composite resins (e.g., Bulk-fill), which are 
specifically designed for posterior use and allow dentists to place restorations faster and easier [3].

New Bulk-fill composites reduce the need for the incremental placement of material [4]. In addition, new Bulkfill composites reduce polymerization shrinkage, provide excellent adaptation and handling, prevent postoperative sensitivity, provide lasting marginal integrity, improved aesthetics, durability, and more working time, and eliminate the need for placing and curing multiple layers of composite (high depth of curing) for direct posterior composite restorations [5]

The longevity of any restoration is one of the most important factors determining its success. A highly polished surface restoration greatly contributes to an increase in longevity and esthetic quality of composite restoration [6 - 8]. Oral biofilms attach to both teeth surfaces and dental material surfaces in oral cavities. Oral biofilms are the source of pathogenesis for periodontal disease, dental caries, secondary caries, and peri-implantitis, which ultimately lead to the failure of restorations [9, 10]. Many studies have demonstrated that unpolished surfaces/rough surfaces can accumulate more dental biofilm than polished surfaces, including resin-based composites, ceramics, implant abutments, and denture bases $[11,12]$

Smooth, highly polished composite restorations are esthetically pleasing, allow them to easily maintain oral hygiene, and, owing to less biofilm formation, are more longlasting than rough restorations [13, 14]. The material surfaces are prone to discoloration, plaque accumulation, gingival irritation, and secondary caries owing to inadequate finishing/polishing procedures. The rough surface may also affect the wear properties and marginal integrity of posterior composite resin restorations [15 - 17]. Various brands of finishing and polishing systems are available that produce different surface characteristics for composite restorations. However, there is a lack of sufficient information regarding the best method and material used to finish and polish Bulk-fill composites. Therefore, the aim of this in vitro study was to use a profilometer to investigate and compare the surface roughness $(\mathrm{Ra})$ of various Bulk-fill composites polished with three different brands of finishing and polishing systems. The null hypothesis was that the surface of all tested Bulk-fill composites would exhibit the same $\mathrm{Ra}$ across all three finishing/polishing systems.

\section{MATERIALS AND METHODS}

This study was approved by the institutional review board/CDRC of King Saud University (Reg. \# E-18-3347). In this study, one conventional [Filtek XT Z350 ${ }^{\circledR}$ (FiltekZ350)] and three Bulk-fill [Filtek Bulk-fill ${ }^{\circledR}$ (Filtek-BF); SonicFill Bulk-fill $^{\circledR} \quad$ (SonicFill-BF); SDR Bulk-fill ${ }^{\circledR} \quad$ (SDR-BF)] commercially available resin-based composites with different types of resin and filler particles were tested to determine Ra for three finishing and polishing systems [Astropol ${ }^{\circledR}$ (Astropol); PoGo $^{\circledR}$ (PoGo); Sof-LexTM ${ }^{\circledR}$ (SofLex)] (Table 1).

\subsection{Sample Size Calculation and Specimen Preparation}

At the alpha of 0.05 , with the power of 0.95 , and the effect size/marginal error of 0.5 , the total sample size for the four composite materials to be finished and polished across the three systems was 120 . Using a stainless steel mold, 30 discs with a $10-\mathrm{mm}$ diameter and 2-mm thickness were fabricated from each composite material. Each material was placed in a stainless steel mold and pressed over the material using a clear matrix strip (Mylar strip, Yates and Bird/Motloid, Chicago, IL, USA); thus, a smooth bubble-free surface of each specimen was produced. Then, all disc-shaped specimens were lightcured for $20 \mathrm{~s}$ using a handheld light-curing unit (Spectrum 800; Dentsply Inc., York, PA, USA) with the output of 1340 $\mathrm{MW} / \mathrm{cm}^{2}$. Next, the roughening of all specimen surfaces was performed using AUTOMATA and 120-grit carbimet paper discs at $20 \mathrm{rpm}$ for $20 \mathrm{~s}$.

\subsection{Finishing and Polishing}

After roughening, all 30 specimens from each composite material group were further randomly subdivided (random draw method) into three groups of 10 specimens each to be finished/polished, depending on the three types of finishing/polishing procedures used in the study. Each specimen was subjected to the finishing/polishing procedure according to the manufacturer's instructions regarding the speed of handpiece, material application method, quantity of material, water utilized, and time used to apply the handpiece (Table 1). As the specimens had a flat surface, the motion of the handpiece was simply from right to left. The finishing/polishing procedure was performed by the same operator to prevent interoperator variations in the surface characteristics of the specimens. Then, the samples were kept in normal saline at room temperature $\left(15-20^{\circ} \mathrm{C}\right)$ until the time of Ra measurement.

\subsection{Surface Roughness Test}

The Ra values of all group specimens were determined in micrometers $(\mu \mathrm{m})$ using a three-dimensional (3D) profilometer (Contour-GT-X ${ }^{\circledR}$, 3D Optical Microscope, Bruker Nano Surfaces Division, San Jose, CA, USA). The 3D specimen surfaces were scanned using a 3D profiling system, and the Ra of the specimens were calculated using a 3D software (Vision64®, Operation and Analysis Software, Bruker Nano Surfaces Division, San Jose, CA, US). Three traces were recorded for each specimen perpendicular to the finishing and polishing scratch directions, and the mean value of the three traces was considered as the final $\mathrm{Ra}$ value for each specimen (Fig. 1).

\subsection{Data Analysis}

The data were analyzed using the SPSS version 21.0 (IBM Inc., Chicago, IL, USA) statistical software. The mean Ra values $(\mu \mathrm{m})$ were tabulated in columns, and descriptive statistics (mean \pm standard deviations) were used to describe the quantitative outcome of each group. The two-way analysis of variance was used to compare the mean Ra values of four composite materials tested (FiltekZ350, Filtek-BF, SonicFill$\mathrm{BF}$ and SDR-BF) using three polishing systems (Astropol, 
PoGo, SofLex). Post Hoc Tukey's multiple comparison tests were used to compare the mean Ra values between different pairs of polishing systems and composite materials. The pvalue of $<0.05$ was used as the cut-off for statistical significance.

Table 1. Description of the materials used/tested in this study.

\begin{tabular}{|c|c|c|c|c|}
\hline S. No. & Groups & Trade Name & Manufacturer & Description \\
\hline \multirow[t]{4}{*}{$\begin{array}{c}\text { Composite } \\
\text { materials }\end{array}$} & \begin{tabular}{|l|} 
FiltekZ350 \\
\end{tabular} & $\begin{array}{c}\text { Filtek Z350 } \\
\text { conventional composite }\end{array}$ & 3M ESPE & $\begin{array}{l}\text { Resin: BisGMA, UDMA, TEGDMA, and BisEMA resins } \\
\text { Filler: Combination of non-agglomerated/non-aggregated } 20 \mathrm{~nm} \text { silica } \\
\text { filler, non-agglomerated/non-aggregated 4-11-nm zirconia filler and } \\
\text { aggregated zirconia/silica cluster filler (20-nm silica and 4-11-nm zirconia } \\
\text { particles) }\end{array}$ \\
\hline & Filtek-BF & $\begin{array}{l}\text { Filtek Bulk-fill }^{\circledR} \\
\text { composite }\end{array}$ & 3M ESPE & $\begin{array}{c}\text { Resin: BisGMA, BisEMA, UDMA, and Procrylat } \\
\text { Filler: Combination of ytterbium trifluoride and zirconia/silica particles }\end{array}$ \\
\hline & \begin{tabular}{|l|} 
SonicFill-BF \\
\end{tabular} & $\begin{array}{l}\text { SonicFill Bulk-fill } \\
\text { composite }\end{array}$ & Kerr & $\begin{array}{l}\text { Resin: } \mathrm{BisGMA} \text { TEGDMA, EBPDMA } \\
\text { Filler: } \mathrm{SiO}_{2} \text {, glass, oxides, chemicals }\end{array}$ \\
\hline & SDR-BF & $\begin{array}{l}\text { SDR Bulk-fill } \\
\text { composite }\end{array}$ & Dentsply & $\begin{array}{l}\text { Resin: Modified UDMA, TEGDMA, EBPDMA } \\
\text { Filler: Barium and strontium F-AI-silicate }\end{array}$ \\
\hline \multirow[t]{3}{*}{$\begin{array}{l}\text { Finishing and } \\
\text { Polishing } \\
\text { Materials }\end{array}$} & Astropol & Astropol $^{\mathbb{B}}$ & Ivoclar Vivadent & $\begin{array}{l}\text { 3-Step finishing and polishing system: } \\
\text { Astropol F: Silicon carbide particles and color pigments. } \\
\text { Astropol P: Silicon carbide particles and color pigments. } \\
\text { Astropol HP: Diamond particles, aluminum oxide, titanium oxide, and iron } \\
\text { oxide }\end{array}$ \\
\hline & PoGo & Enhance $^{\circledR} \mathrm{PoGo}^{\circledR}$ & Dentsply & $\begin{array}{l}\text { 1-Step diamond micro polishers composed of pre-mounted, diamond- } \\
\text { impregnated polishers }\end{array}$ \\
\hline & SofLex & $\begin{array}{l}\text { Sof-LexTM } \\
\text { Spiral finishing and } \\
\text { polishing wheels }\end{array}$ & 3M ESPE & $\begin{array}{l}\text { 2-Step finishing and polishing system composed of a thermoplastic } \\
\text { elastomer impregnated with aluminum oxide particles }\end{array}$ \\
\hline
\end{tabular}

BisGMA: bisphenol A-glycidyl methacrylate; UDMA: Urethane dimethacrylate; TEGDMA: Triethylene-glycol-dimethacrylate; BisEMA: bisphenol A glycol dimethacrylate; EBPDMA: ethoxylated BisGMA.

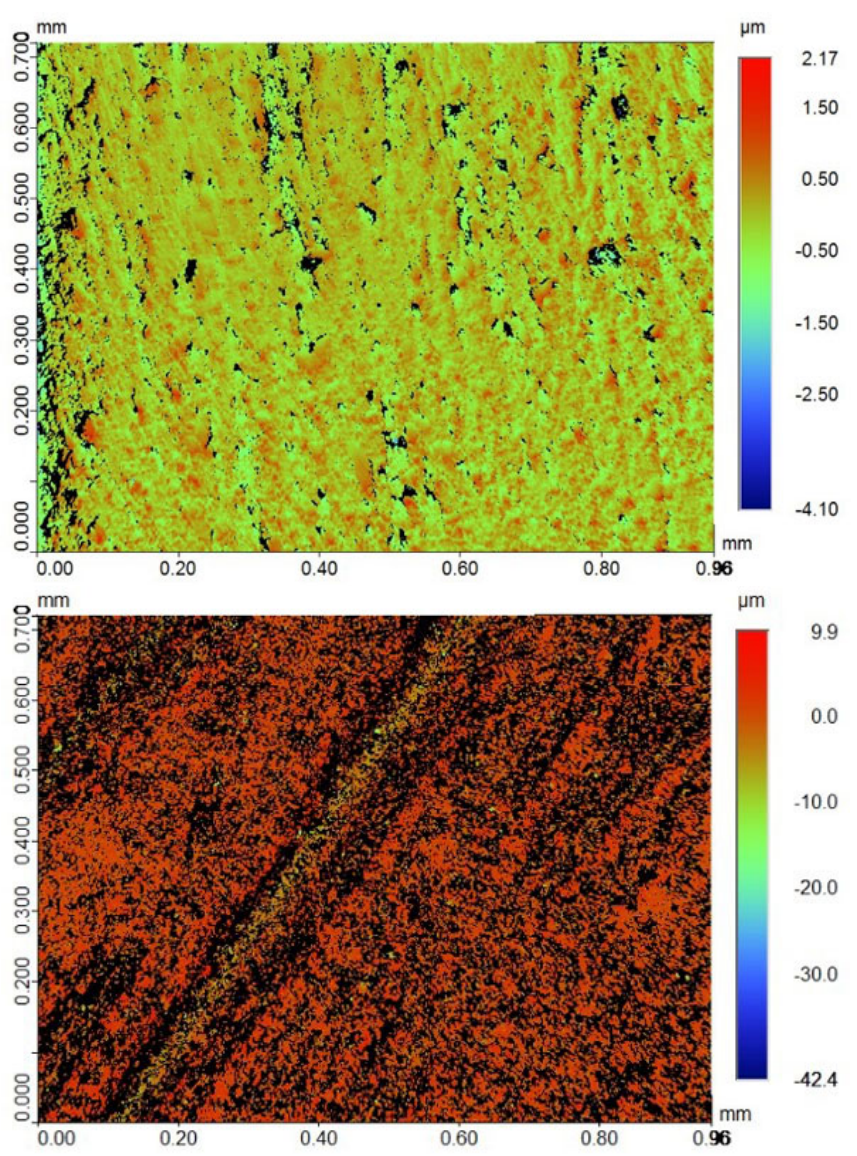




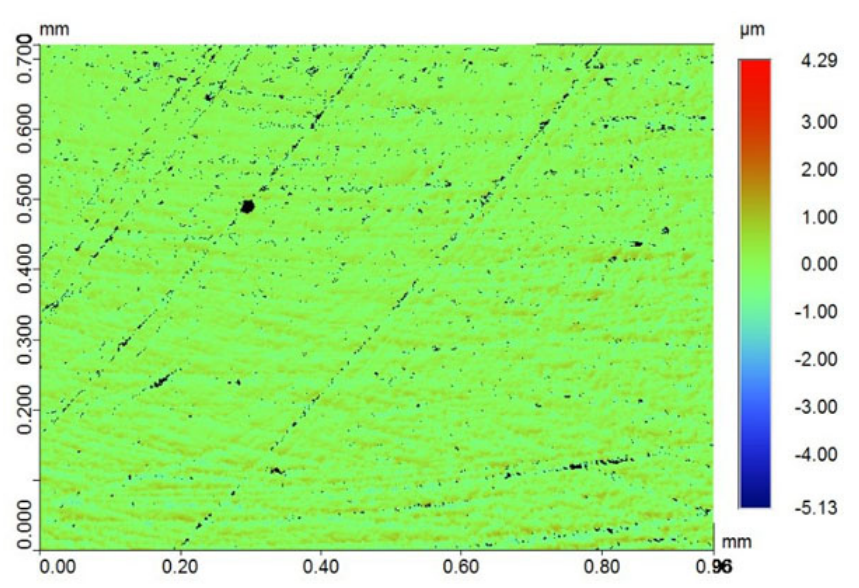

Fig. (1). Profilometric images of surface roughness for the three polishing systems. a: Smoothest surface of SonicFill-BF obtained using the PoGo; b: Roughest surface of SDR-BF obtained using the Astropol system; c: Smoothest surface of FeltikZ350 among all groups obtained using the Soflex system.

\section{RESULTS}

In this study, the Ra values of four composite restorative materials were measured and compared. The measurements were recorded after the specimens of each composite group were subjected to three different finishing/polishing procedures/protocols. The normality of all data was evaluated with the Shapiro-Wilk test and determined to be normally distributed for all groups $(\mathrm{P}>0.05)$.

Variations in the $\mathrm{Ra}$ values produced with three finishing/polishing systems existed among the composite materials tested in this study. Statistically significant differences $(\mathrm{P}<0.05)$ were observed between the Ra values of all composite material groups tested across the three finishing/polishing systems (Fig. 2). The two-way ANOVA analysis did not indicate a significant difference between the three finishing systems within FiltekZ350, Filtek-BF, and SDR-BF ( $P$ > 0.05). However, only SonicFill-BF showed a significant difference $(\mathrm{P}=0.003)$ in the Ra values with all three finishing/polishing systems (Table 2). In addition, there was an interaction between materials and finishing systems $(\mathrm{P}$-value $=$ 0.044).

Table 2. Descriptive statistics with the mean, standard deviation, and ANOVA results of surface roughness (Ra) for all tested composite materials for the finishing/polishing systems $(\mathrm{N}=120)$.

\begin{tabular}{|c|c|c|c|c|c|c|}
\hline Composite Material & Finishing/Polishing System & Mean & \begin{tabular}{|l|} 
Std. Deviation \\
\end{tabular} & *ANOVA P-value & Lower Bound & Upper Bound \\
\hline \multirow{4}{*}{$\begin{array}{l}\text { FiltekZ350 } \\
(\mathrm{n}=10)\end{array}$} & Astropol & 0.411 & 0.109 & \multirow[t]{3}{*}{0.183} & 0.261 & 0.562 \\
\hline & PoGo & 0.381 & 0.185 & & 0.230 & 0.532 \\
\hline & SofLex & 0.305 & 0.064 & & 0.154 & 0.455 \\
\hline & Total & 0.365 & 0.119 & & 0.215 & 0.516 \\
\hline \multirow{4}{*}{$\begin{array}{c}\text { Filtek-BF } \\
(\mathrm{n}=10)\end{array}$} & Astropol & 0.471 & 0.127 & \multirow[t]{3}{*}{0.610} & 0.320 & 0.621 \\
\hline & PoGo & 0.531 & 0.154 & & 0.380 & 0.682 \\
\hline & SofLex & 0.515 & 0.137 & & 0.364 & 0.665 \\
\hline & Total & 0.505 & 0.139 & & 0.354 & 0.656 \\
\hline \multirow{4}{*}{$\begin{array}{l}\text { SonicFill-BF } \\
\quad(\mathrm{n}=10)\end{array}$} & Astropol & 0.646 & 0.210 & \multirow[t]{3}{*}{0.003} & 0.496 & 0.797 \\
\hline & PoGo & 0.337 & 0.039 & & 0.187 & 0.488 \\
\hline & SofLex & 0.622 & 0.280 & & 0.471 & 0.773 \\
\hline & Total & 0.535 & 0.176 & & 0.384 & 0.686 \\
\hline \multirow{4}{*}{$\begin{array}{l}\text { SDR-BF } \\
(\mathrm{n}=10)\end{array}$} & Astropol & 0.984 & 0.528 & \multirow[t]{3}{*}{0.159} & 0.833 & 1.135 \\
\hline & PoGo & 0.636 & 0.233 & & 0.485 & 0.786 \\
\hline & SofLex & 0.812 & 0.360 & & 0.661 & 0.963 \\
\hline & Total & 0.810 & 0.373 & & 0.659 & 0.961 \\
\hline
\end{tabular}

\footnotetext{
*The mean difference is significant at the $\mathrm{P}<0.05$ level.
} 


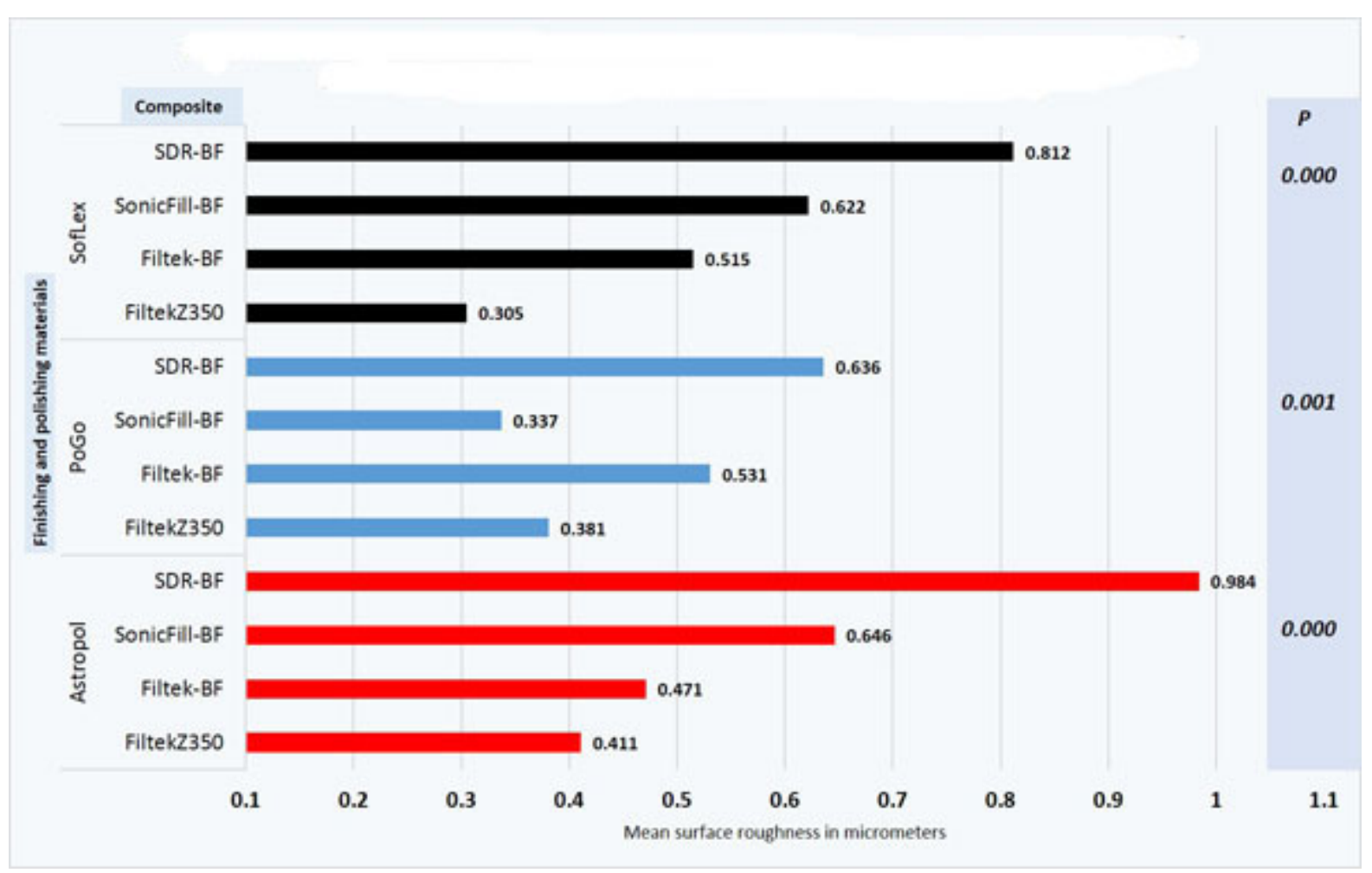

Fig. (2). Descriptive statistics with the mean, standard deviation, and ANOVA results of surface roughness (Ra) for tested composite materials $(\mathrm{N}=$ 120).

Table 3. Multiple comparisons of the surface roughness (Ra) values between the groups by the Post Hoc Tukey HSD test.

\begin{tabular}{|c|c|c|c|}
\hline Finishing/Polishing System & Composite Material & Groups & $*$ Sig. \\
\hline \multirow{6}{*}{ Astropol } & \multirow[t]{3}{*}{ FiltekZ350 } & Filtek-BF & 0.970 \\
\hline & & SonicFill-BF & 0.302 \\
\hline & & SDR-BF & 0.001 \\
\hline & \multirow[t]{2}{*}{ Filtek-BF } & SonicFill-BF & 0.552 \\
\hline & & SDR-BF & 0.002 \\
\hline & SonicFill-BF & SDR-BF & 0.069 \\
\hline \multirow{6}{*}{ PoGo } & \multirow[t]{3}{*}{ FiltekZ350 } & Filtek-BF & 0.210 \\
\hline & & SonicFill-BF & 0.939 \\
\hline & & SDR-BF & 0.009 \\
\hline & \multirow[t]{2}{*}{ Filtek-BF } & SonicFill-BF & 0.210 \\
\hline & & SDR-BF & 0.067 \\
\hline & SonicFill-BF & SDR-BF & 0.002 \\
\hline \multirow{6}{*}{ SofLex } & \multirow[t]{3}{*}{ FiltekZ350 } & Filtek-BF & 0.223 \\
\hline & & SonicFill-BF & 0.027 \\
\hline & & SDR-BF & 0.000 \\
\hline & \multirow[t]{2}{*}{ Filtek-BF } & SonicFill-BF & 0.750 \\
\hline & & SDR-BF & 0.042 \\
\hline & SonicFill-BF & SDR-BF & 0.305 \\
\hline
\end{tabular}

*The mean difference is significant at the $\mathrm{P}<0.05$ level.

Among the composite materials, SDR-BF and FeltikZ350 showed the highest $(0.810 \pm 0.373 \mu \mathrm{m})$ and lowest $(0.365 \pm$ $0.119 \mu \mathrm{m}$ ) Ra values, respectively (Table 2 ). Individually, the highest $\mathrm{Ra}(0.984 \pm 0.528 \mu \mathrm{m})$ was recorded for SDR-BF when it was finished/polished with Astropol. SonicFill-BF (0.337 \pm
$0.039 \mu \mathrm{m})$ and $\operatorname{SDR}-\mathrm{BF}(0.636 \pm 0.233 \mu \mathrm{m})$ composite materials obtained their lowest $\mathrm{Ra}$ values when they were finished/polished with the PoGo system.

Multiple comparisons of the Ra values of all composite test groups for three finishing and polishing systems are shown in 
Table 3. The SofLex fishing/polishing system revealed the highest number of significant differences among the composite groups. This result also confirmed the presence of variations between the $\mathrm{Ra}$ values of the composites produced using different finishing and polishing systems.

\section{DISCUSSION}

In this in vitro research study, the Ra of four commonly used composite restorative materials that were finished/polished with three different systems were evaluated using the test specimens of identical shape and dimensions under the same testing conditions using a 3D non-contact profilometer. The recorded $\mathrm{Ra}$ values were useful for the assessment and comparison between the composite materials tested.

The methodology used in this study for measuring $\mathrm{Ra}$ values using a $3 \mathrm{D}$ non-contact profilometer provides good resolution of the traced surface and has been reported by several researchers to be the optimal method for measuring Ra $[10,12,18-20]$. The advantages of an optical profilometer are that it uses a beam of light to detect small variations, provides a quantitative aspect through the calculation of $\mathrm{Ra}$, and the same specimens can be reused and reobserved after successive time intervals. ${ }^{21}$ The recorded Ra value is a helpful general indicator of surface topography; it is useful and easy to understand value; therefore, it is possible to compare $\mathrm{Ra}$ of different materials and also compare the results with those from other studies and standards. ${ }^{18-21}$

Previous studies have confirmed the differences in Ra of various composite restorative materials that were finished and polished by different materials and systems using standardized in vitro specimen preparations [22, 23]. Most Ra tests provide limited information/correlation with clinical performance; nevertheless, in vitro experiments allow the comparative assessment and ranking of chemically different materials under standardized testing conditions. However, testing conditions that are similar to the clinical scenario are always considered to be useful $[10,12,19,22]$

According to the results of this study, significant differences in the Ra of tested composite materials that were finished and polished by three different systems were revealed. Among the tested materials, FiltekZ350 (conventional composite) possessed the smoothest surface with the lowest Ra values $(0.365 \pm 0.119)$, and SDR-BF (Bulk-fill composite) possessed the roughest surface with the highest $\mathrm{Ra}$ values $(0.810 \pm 0.373)$. Thus, based on these results, the null hypothesis of the absence of difference in Ra between the materials after finishing/polishing with different systems was rejected.

In this study, the order of surface roughness ranked according to composite groups was Filtek XT Z350 ${ }^{\circledR}<$ Filtek Bulk-fill $^{\circledast}<$ SonicFill Bulk-fill $^{\circledast}<$ SDR Bulk-fill $^{\circledR}$. The overall lowest Ra value was recorded for the control FiltekZ350 of the conventional composite. Filtek XT $\mathrm{Z350}^{\circledR}$ contains a combination of a non-agglomerated/non-aggregated (20-nm nanosilica filler) and loosely bound agglomerated zirconia/silica nanocluster with the filler size of 5-20 nm and a cluster particle size of $0.6-1.4 \mu \mathrm{m}$. As this composite contains nanofillers, it has lower surface roughness than other materials after polishing. Filtek-BF exhibited the next smoothest surface, and multiple comparisons revealed non-significant differences between this group and the FiltekZ350 control group. These non-significant differences can be attributed to the brand similarity of the two groups.

In our study, SDR Bulk-fill ${ }^{\circledR}$ exhibited the roughest surfaces with the highest Ra values. This finding is similar to the results reported by Kumari et al., [22] Nair et al., [18] and other researchers. This reported high $\mathrm{Ra}$ is attributed to the lower filler loading and polymerization modulator that is chemically embedded at the center of the polymerizable resin, which is the backbone of SDR Bulk-fill ${ }^{\circledR 23-25}$

Among all groups tested with each finishing/polishing material, the lowest Ra was observed for Filtek XT Z350 ${ }^{\circledR}$ that was polished with Sof-LexTM ${ }^{\circledR}$. Previous studies have reported that aluminum oxide discs are ideal for producing low Ra. [7, $22,23]$. This is attributed to the ability of the Sof-LexTM ${ }^{\circledR}$ system to abrade filler particles and resin matrix at equal rates without dislodging the filler particles and gouging into the material. $[18,22,23]$ On the other hand, the smoothest surfaces of SDR Bulk-fill ${ }^{\circledR}$ and SonicFill Bulk-fill ${ }^{\circledR}$ were obtained when they were finished with the PoGo ${ }^{\circledR}$ system. A previous study ${ }^{26}$ on the effect of a one-step polishing system on the Ra of composite concluded that among the polishing systems tested, the PoGo system produced the smoothest finishing for all conventional composite resins. ${ }^{26}$ The highest $\mathrm{Ra}$ value was recorded for SDR Bulk-fill ${ }^{\circledR}$ when it was finished with the Astropol $^{\circledR}$ system. This result was obtained possibly due to the coarser abrasive particles in the Astropol ${ }^{\circledR}$ system than in other systems [27].

Some limitations of this study are the flat surface of the sample (which is absent in clinical restorations) and the limitations associated with the in vitro research studies, and the absence of clinical environment because there may be changes in in vivo results. In this study, the Ra of the groups was measured and compared after roughening the specimens, and for future investigations, it is advised to do the initial $\mathrm{Ra}$ as well for a better comparison. Further research using other available systems with larger sample size is recommended for future studies. Further studies with samples prepared in the teeth to simulate convex and concave tooth surfaces are required to investigate how these resins and polishing systems will perform under clinical conditions.

\section{CONCLUSION}

Within the limitations of this study, the following conclusions can be made:

- Variations existed in the surface roughness of composite materials that were finished/polished with different systems.

- Finishing and polishing techniques greatly affect the surface roughness of different Bulk-fill composites.

- Among the tested composite materials, Filtek Z350 ${ }^{\circledR}$ showed the smoothest surface/lowest surface 
roughness values out of all polishing systems tested.

- Among the Bulk-fill composites, SonicFill Bulk-fill ${ }^{\circledR}$ that was polished with the PoGo ${ }^{\circledR}$ system produced the best results in terms of surface roughness.

- SDR Bulk-fill ${ }^{\circledR}$ exhibited the highest surface roughness, which was greatly reduced when the material was polished with the PoGo ${ }^{\circledR}$ system.

\section{ETHICS APPROVAL AND CONSENT TO PARTI-} CIPATE

Not applicable.

\section{HUMAN AND ANIMAL RIGHTS}

Not applicable.

\section{CONSENT FOR PUBLICATION}

Not applicable.

\section{AVAILIBILITY OF DATA AND MATERIALS}

Not applicable.

\section{FUNDING}

None.

\section{CONFLICT OF INTEREST}

The authors declare no conflict of interest, financial or otherwise.

\section{ACKNOWLEDGEMENTS}

Declared none.

\section{REFERENCES}

[1] Bohaty BS, Ye Q, Misra A, Sene F, Spencer P. Posterior composite restoration update: focus on factors influencing form and function. Clin Cosmet Investig Dent 2013; 5: 33-42.

[http://dx.doi.org/10.2147/CCIDE.S42044] [PMID: 23750102]

[2] Chesterman J, Jowett A, Gallacher A, Nixon P. Bulk-fill resin-based composite restorative materials: a review. Br Dent J 2017; 222(5): 337-44.

[http://dx.doi.org/10.1038/sj.bdj.2017.214] [PMID: 28281590]

[3] Van Ende A, De Munck J, Lise DP, Van Meerbeek B. Bulk-Fill composites: A review of the current literature. J Adhes Dent 2017; 19(2): 95-109.

[http://dx.doi.org/10.3290/j.jad.a38141] [PMID: 28443833]

[4] Walter R. Critical appraisal: bulk-fill flowable composite resins. J Esthet Restor Dent 2013; 25(1): 72-6. [http://dx.doi.org/10.1111/jerd.12011] [PMID: 23374413]

[5] Baroudi K, Rodrigues JC. Flowable resin composites: A systematic review and clinical considerations. J Clin Diagn Res 2015; 9(6): ZE18-24.

[http://dx.doi.org/10.7860/JCDR/2015/12294.6129] [PMID: 26266238]

[6] Yap AU, Ang HQ, Chong KC. Influence of finishing time on marginal sealing ability of new generation composite bonding systems. J Oral Rehabil 1998; 25(11): 871-6.

[http://dx.doi.org/10.1046/j.1365-2842.1998.00316.x] [PMID: 9846907]

[7] Chour RG, Moda A, Arora A, Arafath MY, Shetty VK, Rishal Y. Comparative evaluation of effect of different polishing systems on surface roughness of composite resin: An in vitro study. J Int Soc Prev Community Dent 2016; 6(Suppl. 2): S166-70. [http://dx.doi.org/10.4103/2231-0762.189761] [PMID: 27652251]

[8] Celik C, Ozgünaltay G. Effect of finishing and polishing procedures on surface roughness of tooth-colored materials. Quintessence Int
2009; 40(9): 783-9.

[PMID: 19862405]

[9] Hao Y, Huang X, Zhou X, et al. Influence of Dental Prosthesis and Restorative Materials Interface on Oral Biofilms. Int J Mol Sci 2018; 19(10): 3157.

[http://dx.doi.org/10.3390/ijms19103157] [PMID: 30322190]

[10] Gharechahi M, Moosavi H, Forghani M. Effect of Surface Roughness and Materials Composition. J Biomater Nanobiotechnol 2012; (03): 541-6.

[http://dx.doi.org/10.4236/jbnb.2012.324056]

[11] Habib SR, Nakshabandi AZ, Al Shawi AA, Allohaidan FA, Al Kurdi RB, AlSarhan M. Degree of streptococcus mutans colonization on common restorative materials subjected to wear cycle. Int $\mathrm{J}$ Prosthodont 2020. Epub ahead of print [http://dx.doi.org/10.11607/ijp.6519] [PMID: 32588997]

[12] Haralur SB. Evaluation of efficiency of manual polishing over autoglazed and overglazed porcelain and its effect on plaque accumulation. J Adv Prosthodont 2012; 4(4): 179-86. [http://dx.doi.org/10.4047/jap.2012.4.4.179] [PMID: 23236568]

[13] Al-Sarhan M A, Habib S R, AlJamhan A S, AlMutairi H F, Alohali I O, Aldubayyan R A. Effect of Finishing and Polishing Bulk-Fill Composites on Salivary and Streptococcus mutans Adhesion. BioscBiotechResComm 2020; 13(1)

[http://dx.doi.org/10.21786/bbrc/13.1/44]

[14] Da Costa J, Ferracane J, Paravina RD, Mazur RF, Roeder L. The effect of different polishing systems on surface roughness and gloss of various resin composites. J Esthet Restor Dent 2007; 19(4): 214-24. [http://dx.doi.org/10.1111/j.1708-8240.2007.00104.x] [PMID: 17635330]

[15] Gedik R, Hürmüzlü F, Coşkun A, Bektaş OO, Ozdemir AK. Surface roughness of new microhybrid resin-based composites. J Am Dent Assoc 2005; 136(8): 1106-12.

[http://dx.doi.org/10.14219/jada.archive.2005.0314] [PMID: 16161365]

[16] Barbosa SH, Zanata RL. Navarro MF de Lima, Nunes OB. Effect of different finishing and polishing techniques on the surface roughness of microfilled, hybrid and packeble composite resins. Braz Dent J 2005; 16: 39-44.

[http://dx.doi.org/10.1590/S0103-64402005000100007] [PMID: 16113932]

[17] Kaminedi RR, Penumatsa NV, Priya T, Baroudi K. The influence of finishing/polishing time and cooling system on surface roughness and microhardness of two different types of composite resin restorations. J Int Soc Prev Community Dent 2014; 4(Suppl. 2): S99-S104. [http://dx.doi.org/10.4103/2231-0762.146211] [PMID: 25558457]

[18] Nair VS, Sainudeen S, Padmanabhan P, Vijayashankar LV, Sujathan U, Pillai R. Three-dimensional evaluation of surface roughness of resin composites after finishing and polishing. J Conserv Dent 2016; 19: 91-5.

[19] Abdelmegid FY, Salama FS, Al-Jameel MM, Al-Rasheed TT, ElSharawy MA. Effects of fruit drinks on surface roughness of two esthetic restorative materials. Stomatologija 2019; 21(2): 47-52. [PMID: 32108656]

[20] Alp G, Johnston WM, Yilmaz B. Optical properties and surface roughness of prepolymerized poly(methyl methacrylate) denture base materials. J Prosthet Dent 2019; 121(2): 347-52.

[http://dx.doi.org/10.1016/j.prosdent.2018.03.001] [PMID: 30143239]

[21] Habib SR, Alotaibi A, Al Hazza N, Allam Y, AlGhazi M. Two-body wear behavior of human enamel versus monolithic zirconia, lithium disilicate, ceramometal and composite resin. J Adv Prosthodont 2019; 11(1): 23-31.

[http://dx.doi.org/10.4047/jap.2019.11.1.23] [PMID: 30847046]

[22] Kumari CM, Bhat KM, Bansal R, Singh N, Anupama A, Lavanya T. Evaluation of Surface Roughness and Hardness of Newer Nanoposterior Composite Resins after Immersion in Food-Simulating Liquids. Contemp Clin Dent 2019; 10(2): 289-93.

[http://dx.doi.org/10.4103/ccd.ccd_535_18] [PMID: 32308292]

[23] Kumari CM, Bhat KM, Bansal R. Evaluation of surface roughness of different restorative composites after polishing using atomic force microscopy. J Conserv Dent 2016; 19(1): 56-62. [http://dx.doi.org/10.4103/0972-0707.173200] [PMID: 26957795]

[24] Rigo LC, Bordin D, Fardin VP, et al. Influence of Polishing System on the Surface Roughness of Flowable and Regular-Viscosity Bulk Fill Composites. Int J Periodontics Restorative Dent 2018; 38(4): e79-86. [http://dx.doi.org/10.11607/prd.3033] [PMID: 29513777]

[25] Ishii R, Takamizawa T, Tsujimoto A, et al. Effects of finishing and polishing methods on the surface roughness and surface free energy of 
bulk-fill resin composites. Oper Dent 2020; 45(2): E91-E104. [http://dx.doi.org/10.2341/18-246-L] [PMID: 31738697]

[26] Türkün LS, Türkün M. The effect of one-step polishing system on the surface roughness of three esthetic resin composite materials. Oper Dent 2004; 29(2): 203-11
[PMID: 15088733]

27] Hassan AM, Nabih SM, Mossa HM, Baroudi K. The effect of three polishing systems on surface roughness of flowable, microhybrid, and packable resin composites. J Int Soc Prev Community Dent 2015;

5(3): 242-7.

[http://dx.doi.org/10.4103/2231-0762.159965] [PMID: 26236686]

\section{(C) 2021 Al Jamhan et al.}

This is an open access article distributed under the terms of the Creative Commons Attribution 4.0 International Public License (CC-BY 4.0), a copy of which is available at: https://creativecommons.org/licenses/by/4.0/legalcode. This license permits unrestricted use, distribution, and reproduction in any medium, provided the original author and source are credited. 